ORIGINAL ARTICLE

\title{
Head injuries in youth soccer players presenting to the emergency department
}

\author{
W Pickett, S Streight, K Simpson, R J Brison
}

Br J Sports Med 2005;39:226-231. doi: 10.1136/bjsm.2004.013169

Background: There has been recent concern about neuropsychological injuries experienced by soccer players, particularly related to the purposeful heading of the ball. There are few population based analyses examining whether this is a legitimate concern.

Objectives: To explore, using an existing injury surveillance system, one of many parts of this issue: acute injuries requiring emergency medical care experienced by youth soccer players.

See end of article for authors' affiliations Methods: Descriptive epidemiological analysis of emergency department injury surveillance data (19962001) for youths aged 10-24 years from the Kingston sites of the Canadian Hospital Injury Reporting and Prevention Program.

Correspondence to: Dr Pickett, Department of Emergency Medicine, Queen's University, c/o Kingston General Hospital, Angada 3, Kingston, Ontario K7L 2V7, Canada; simpsonk@ kgh.kari.net

Results: A total of 1714 cases of soccer injury were identified (mean 286 a year); 235 (13.7\%) involved diagnoses of injuries to the head. Leading mechanical factors resulting in head injury were contact with other players or persons $(153 / 235 ; 65.1 \%)$ and balls $(62 / 235 ; 26.4 \%)$. Heading was reported in $4 / 62$ $(6 \%)$ of the ball contact injuries, and attempted heading was reported in 15/153 (9.8\%) of the cases involving person to person contact. Unspecified head to head contact between players was reported in 39 cases.

Conclusions: Minor head injuries that result in emergency medical treatment do not happen often in youth soccer, and very few can be attributed to the purposeful heading of the ball. Player contact injuries appear Accepted 27 September 2004 to be a more important injury control concern. This study informs one of many aspects of the soccer heading injury debate.

S occer is the most popular team sport in the world and participation continues to grow. One of its main attractions is that it is viewed as a safe sport with relatively limited physical contact. ${ }^{12}$ Existing studies suggest that acute soccer injuries are concentrated in the lower extremities $^{3}$ consistent with the nature of the physical play involved. However, soccer is a unique sport in that there is purposeful use of the head to direct and control the ball. Heading, when performed properly, is an exciting and effective component of the sport. It is a difficult technique to teach and its execution requires considerable practice and skill.

There has been recent concern over the role of heading as a risk factor for neurotrauma. The contributions of heading to the occurrence of mild head injury, ${ }^{4}$ concussion, ${ }^{5}$ and cognitive impairment $^{6}$ have been discussed. Numerous studies have examined chronic neuropsychological deficits associated with prolonged exposures to soccer and heading, beginning with early studies of professional soccer players from the Netherlands. ${ }^{6-11}$ These studies are often cited as proof that heading is the cause of cognitive deficiencies, but have also been criticised for methodological deficiencies. ${ }^{12}$ In a related Dutch study that compared 33 amateur soccer players with 27 amateur athletes involved in swimming and track (controls), Matser et $a l^{13}$ showed that amateur soccer players exhibited impaired performance on tests of planning and memory, and these deficits were inversely related to the number of past concussions. Like the studies that came before, cognitive deficits observed in this study could not be attributed to the purposeful heading of the ball. In another setting, Jordan et al ${ }^{14}$ compared 20 athletes from the 1994 US World Cup soccer team with 20 track athletes, but observed no group differences in clinical signs and symptoms of head injury, as inferred from medical history and magnetic resonance imaging.

Before 1980, soccer often involved the use of leather balls which could result in considerable impact forces, especially under wet conditions. ${ }^{12}$ Recent advancements in technology have led to lighter and water resistant soccer balls which have less impact. ${ }^{12}{ }^{15}$ In addition, younger players are required to use smaller (sizes 4 or less) balls to optimise both safety and skill development. Both of these innovations may have reduced the potential for neurotraumatic injury. ${ }^{16}$

Several levels of research can inform the debate over whether heading places soccer players at risk. One form of evidence is the study of acute head injuries due to purposeful or unintentional heading. Chronic subdural haematoma associated with being struck by a soccer ball has been cited in one case report. ${ }^{17}$ In one of the few other existing studies, ${ }^{13}$ 100 varsity soccer players at Pennsylvania State University were administered a battery of neuropyschological tests before and after a training session. Heading the ball did not appear to lead to any apparent acute changes in cognitive function. To our knowledge, there are no existing epidemiological studies of acute soccer head injuries that result in emergency medical treatment. Our own research setting in Kingston, Ontario is a population based site of the Canadian Hospitals Injury Reporting and Prevention Program (CHIRPP), a national emergency department based injury surveillance programme ${ }^{18}$ We therefore used this opportunity to conduct such an investigation.

The objectives of this epidemiological study were to perform descriptive analyses of acute soccer related injuries, with a specific focus on head trauma and the mechanisms leading to injury among youth soccer players (ages 10-24). We focused on this age group because youth soccer is enormously popular in Canada, and it was felt a priori that this age group would be the most likely to sustain a head trauma from heading because of a high level of exposure to organised play, combined with inexperience. The results 
Table 1 Distribution of soccer injuries by nature of injury, age and sex of patient, Kingston and area, 1996-2001

\begin{tabular}{|c|c|c|c|c|c|c|c|c|c|c|}
\hline \multirow[b]{3}{*}{ Nature of injury } & \multicolumn{8}{|c|}{ Soccer head injuries } & & \\
\hline & \multicolumn{2}{|c|}{$10-14$ years } & \multicolumn{2}{|c|}{$15-19$ years } & \multicolumn{2}{|c|}{$20-24$ years } & \multicolumn{2}{|c|}{$\begin{array}{l}\text { Total soccer head injuries } \\
\text { (10-24 years) }\end{array}$} & \multicolumn{2}{|c|}{$\begin{array}{l}\text { Total soccer injuries } \\
\text { (10-24 years) }\end{array}$} \\
\hline & Male & Female & Male & Female & Male & Female & No & $\%$ & No & $\%$ \\
\hline Open wound & 10 & - & 18 & 5 & 23 & 2 & 58 & 24.7 & 73 & 4.3 \\
\hline Superficial & 13 & 4 & 9 & 5 & 5 & 8 & 44 & 18.7 & 572 & 33.4 \\
\hline Minor head injury & 5 & 4 & 12 & 4 & 6 & 7 & 38 & 16.2 & 38 & 2.2 \\
\hline Eye injury & 10 & 1 & 6 & 7 & 4 & 8 & 36 & 15.3 & 36 & 2.1 \\
\hline Concussion & 6 & 4 & 14 & 3 & 5 & 1 & 33 & 14.0 & 33 & 1.9 \\
\hline Fracture & 2 & - & 6 & 7 & 6 & 2 & 23 & 9.8 & 313 & 18.3 \\
\hline Dental injury & - & - & 2 & - & - & - & 2 & 0.8 & 2 & 0.1 \\
\hline Sprain/strain & - & - & - & - & - & - & - & - & 352 & 20.5 \\
\hline $\begin{array}{l}\text { Injury to muscle, tendon, } \\
\text { or blood vessel }\end{array}$ & - & - & - & - & - & - & - & - & 114 & 6.7 \\
\hline Soft tissue injury & - & - & - & - & - & - & - & - & 108 & 6.3 \\
\hline Dislocation & - & - & - & - & - & - & - & - & 46 & 2.7 \\
\hline Other/unspecified & - & - & - & - & - & 1 & 1 & 0.4 & 27 & 1.6 \\
\hline Total & 46 & 13 & 67 & 31 & 49 & 29 & 235 & 100.0 & 1714 & 100.0 \\
\hline
\end{tabular}

provide practical data that inform the medical debate over whether soccer ball heading is a practice that should be discouraged.

\section{METHODS \\ Injury surveillance}

CHIRPP is an ongoing national, injury surveillance programme which operates in the emergency departments of selected Canadian hospitals. ${ }^{18}$ It began its operation in 10 Canadian paediatric hospitals in 1990, and has since been expanded to include six general hospitals. For each visit to the emergency department, the patient or an accompanying person completes a one page self administered CHIRPP questionnaire which collects information on external causes, circumstances, and factors leading to injury. Basic and clinical information is abstracted from the patient's medical chart.

\section{Regional injury surveillance in Kingston}

Kingston is a Canadian city in Eastern Ontario with a population of about 120 000. Kingston General and Hotel Dieu hospitals have the only two emergency departments in Kingston. Since 1993, injury data from these hospitals have been collected and entered into the national CHIRPP database. The Kingston site is unique in the CHIRPP surveillance programme because of its complete community coverage.

\section{Organised soccer in Kingston and area}

During the outdoor season, there are seven organised youth clubs in the Kingston area, ranging from about 125 to 2350 players (S Kekkas, Ontario Soccer Association, personal communication, 2003). Ten additional youth clubs operate among communities in the wider district surrounding Kingston. Competitive soccer play also occurs in the elementary and high school systems, as well as men's and women's competitive and recreational leagues. Year round play is becoming popular with the establishment of an indoor soccer facility in 1997.

There is no central data source that describes the amounts of time that soccer players in our population spend playing and training for the sport. There are two general age classifications involved (youth and adult, the split occurring at age 18) in organised play, and two levels of competition (recreational and competitive). A typical recreational player will have an outdoor season of 13 weeks with one game and one practice a week. A typical competitive player will have an outdoor season of 16 weeks with one or two games and two or three practices a week, plus a varying number of tournaments and cup matches. Indoor play is less predictable, but occurs over the autumn and winter (October through March) and often involves only one organised session a week among a much more limited player pool.

\section{Case identification and data abstraction}

Records of soccer injuries were abstracted from the Kingston CHIRPP dataset. Eligibility criteria were as follows: patient aged 10-24 years at the time of injury; injury occurred during the calendar years 1996-2001; soccer (organised or unorganised) identified as the activity leading to the injury events in CHIRPP context $\operatorname{codes}^{19}$; body part injured included the head and/or neck (CHIRPP body part codes ${ }^{19}$ 110-140). Younger children were excluded, as heading is discouraged in those age groups and only incidentally becomes part of the game (of the 128 soccer injuries to children $<10$ years during 19962001, 32 were head injuries, and none involved purposeful heading). Available descriptors included age and sex of patient, nature of injury (see below), and level of organisation (organised or unorganised). Written descriptions of the circumstances surrounding each injury event were used to classify mechanical factors leading to injury. CHIRPP disposition $\operatorname{codes}^{19}$ correspond to the level of treatment rendered, and included: 1, advice or observation; 2, treated, follow up as needed; 3, treated, follow up required; 4, hospital admission.

\section{CHIRPP nature of injury codes}

Coding of nature of injury is performed by a single nurse researcher who abstracts information directly from the emergency discharge record. After consulting the "discharge diagnosis" and "medical history" sections of each record, one or more of a series of diagnostic codes are selected. For head injuries, the CHIRPP nature of injury $\operatorname{codes}^{19}$ list a number of possibilities, most commonly: 10, superficial-for example, bruise, abrasion; 11, open wound/laceration; 24, eye injury; 25, dental injury; 41, minor head injury; 42, concussion; 43, intracranial injury. The code selected by the nurse researcher reflects the exact wording written on the discharge summary by attending medical staff.

\section{Analysis}

Records were divided into three age groups (10-14, 15-19, 20-24 years) which corresponded to different levels of physical development and soccer play. Descriptive statistics 

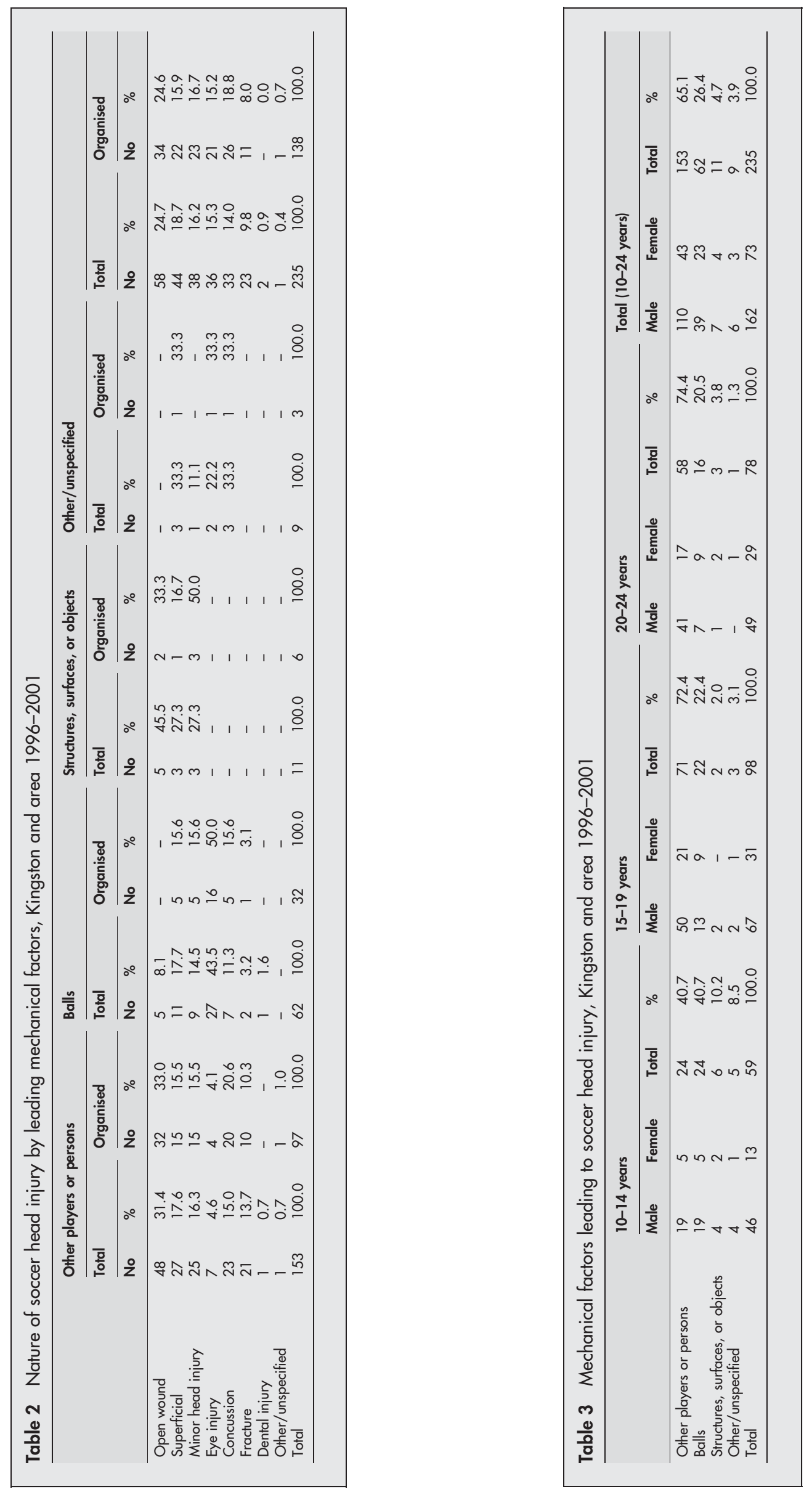

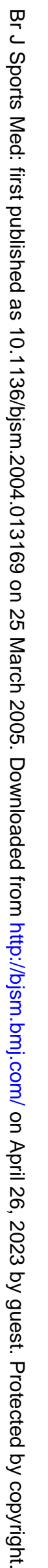


were used to characterise soccer injuries. Head injuries were isolated for specific review. All data management and analyses were conducted in Excel 97.

\section{RESULTS}

\section{General distribution of soccer injuries}

There were 1714 soccer injuries identified for the Kingston population aged 10-24 years (mean 286 a year over six years). More soccer injuries were incurred by male soccer players than female players in all age groups (overall sex ratio 1.6:1). The leading types of soccer injury included superficial injuries $(572 / 1714 ; 33.4 \%)$, sprains/strains $(352 / 1714 ; 20.5 \%)$, and fractures $(313 / 1714 ; 18.3 \%)$ (table 1 ).

\section{Soccer related head injuries}

There were $235 / 1714$ (13.7\%) soccer injuries involving the head (table 1). Of these, $58(24.7 \%)$ were open wounds, 44 $(18.7 \%)$ were superficial injuries, $38(16.2 \%)$ were minor closed head injuries, 36 (15.3\%) were ocular injuries, and 33 $(14.0 \%)$ were concussions (table 1 ). The overall ratio of male:female head injuries was 2.2 to 1 .

Leading mechanical factors associated with head injury were contact with other players or persons (153/235; 65.1\%) and contact with balls $(62 / 235 ; 26.4 \%)$ (table 2$)$. For injuries resulting from player contact, open wounds $(48 / 153 ; 31.4 \%)$, superficial injuries $(27 / 153 ; 17.6 \%)$, and minor closed head injuries $(25 / 153 ; 16.3 \%)$ were the leading types of head injury. Ocular injuries $(27 / 62 ; 43 \%)$, superficial injuries (11/ $62 ; 18 \%)$, and minor closed head injuries $(9 / 62 ; 14 \%)$ were the most common types of injury involving ball contact (table 2). Ball injuries resulted in significantly more eye injuries, and significantly fewer open wounds and fractures than all other injury types $(\mathrm{p}<0.05$; all statistical contrasts $)$.

\section{Heading injuries}

Heading was reported as the mechanism in 4/62 (6\%) of the ball contact injury cases. The first case occurred during unorganised play in the back yard of a house and led to an open wound that was treated in the emergency department with no follow up. The second case occurred during organised play, was diagnosed as a concussion based on clinical signs including nausea, and was treated with advice only. The third also occurred during organised play, was diagnosed as a minor head injury, and was subject to hospital based neurological investigations. The fourth occurred during an unspecified level of play at an unspecified place, and was released from emergency after advice and observation.
Of the cases involving contact with other players or persons, $15 / 153(9.8 \%)$ of the players were attempting to head the ball at the time of injury, and 39/153 (25.5\%) of the cases involved unspecified head to head contact (where heading the ball may have been the intent). Of the 15 attempted heading injuries, 12/15 (80\%) occurred during organised play, and 10/15 (67\%) happened at a soccer pitch or in a gymnasium (the remaining locations were unspecified). Diagnoses associated with the 15 player contact head injuries were open wounds $(8 / 15 ; 53 \%)$, superficial injuries $(4 / 15$; $27 \%)$, minor head injury $(2 / 15 ; 13 \%)$, and facial fracture $(1 / 15 ; 7 \%)$. For unspecified head to head contact $(n=39)$, the most common injuries were open wounds (13/39; 33\%), minor closed head injuries $(8 / 39 ; 20 \%)$, maxillofacial fractures $(7 / 39 ; 18 \%)$, and superficial injuries $(7 / 39 ; 18 \%)$.

\section{Organised play}

More than half $(138 / 235 ; 58.7 \%)$ of the soccer related head injuries occurred during organised games or practices (table 2). Organised play was involved in 97/153 (63.4\%) of the contact injuries with other players or persons and 32/62 $(52 \%)$ of the ball contact injuries. Of the confirmed or possible heading injuries (including confirmed heading, attempted heading, and unspecified head to head contact), $42 / 58(72 \%)$ occurred during organised play.

\section{Other results}

Older players (15-24 years) experienced more head injuries resulting from contact with other players or persons than younger players $(p<0.001$; table 3$)$. Consistent with reduced levels of player contact, younger players were more often injured from ball contact $(\mathrm{p}<0.01)$. Only $3 / 235(1.3 \%)$ of the head injuries required admission to hospital (table 4 ), all for maxillofacial fractures and all in the 20-24 year age group. Proportions of cases requiring follow up medical treatment were $14 / 59$ (24\%), 45/98 (46\%), and 35/78 (45\%) for ages 10 $14,15-19$, and $20-24$ respectively $(\mathrm{p}=0.01)$.

\section{DISCUSSION}

Although many soccer injuries were documented in our study, these injury events typically did not lead to major medical sequelae. Recurrent types of injury included open wounds, fractures, sprains and strains, and other soft tissue injuries. A modest portion of the soccer injuries were sustained to the head $(235 / 1714 ; 13.7 \%)$. Minor head injuries and concussions were most commonly caused by contact with players. In total, there was little evidence to suggest that heading was a major cause of acute neurotraumatic injury,

Table 4 Treatment of soccer head injuries by nature of injury and mechanical factor, Kingston and area 1996-2001

\begin{tabular}{|c|c|c|c|c|c|c|c|c|c|c|}
\hline & \multicolumn{2}{|c|}{$\begin{array}{l}\text { Advice or } \\
\text { observation }\end{array}$} & \multicolumn{2}{|c|}{$\begin{array}{l}\text { Treated, follow } \\
\text { up as needed }\end{array}$} & \multicolumn{2}{|c|}{$\begin{array}{l}\text { Treated, follow } \\
\text { up required }\end{array}$} & \multicolumn{2}{|c|}{$\begin{array}{l}\text { Hospital } \\
\text { admission }\end{array}$} & \multicolumn{2}{|c|}{$\begin{array}{l}\text { Total soccer } \\
\text { head injuries }\end{array}$} \\
\hline & No & $\%$ & No & $\%$ & No & $\%$ & No & $\%$ & No & $\%$ \\
\hline \multicolumn{11}{|l|}{ Nature of injury } \\
\hline Open wound & 2 & 4.4 & 13 & 14.0 & 43 & 45.7 & - & - & 58 & 24.7 \\
\hline Superficial & 10 & 22.2 & 30 & 32.3 & 4 & 4.3 & - & - & 44 & 18.7 \\
\hline Minor head injury & 15 & 33.3 & 20 & 21.5 & 3 & 3.2 & - & - & 38 & 16.2 \\
\hline Eye injury & - & - & 9 & 9.7 & 27 & 28.7 & - & - & 36 & 15.3 \\
\hline Concussion & 18 & 40.0 & 15 & 16.1 & - & - & - & - & 33 & 14.0 \\
\hline Fracture & - & - & 5 & 5.4 & 15 & 16.0 & 3 & 100.0 & 23 & 9.8 \\
\hline Dental injury & - & - & - & - & 2 & 2.1 & - & - & 2 & 0.9 \\
\hline Other/unspecified & - & - & 1 & 1.1 & - & - & - & - & 1 & 0.4 \\
\hline \multicolumn{11}{|l|}{ Mechanical factor } \\
\hline Other players or persons & 29 & 64.4 & 58 & 62.4 & 64 & 68.1 & 2 & 66.7 & 153 & 65.1 \\
\hline Balls & 12 & 26.7 & 22 & 23.7 & 27 & 28.7 & 1 & 33.3 & 62 & 26.4 \\
\hline Structures, surfaces or objects & 2 & 4.4 & 6 & 6.5 & 3 & 3.2 & - & - & 11 & 4.7 \\
\hline Other/unspecified & 2 & 4.4 & 7 & 7.5 & - & - & - & - & 9 & 3.8 \\
\hline Total & 45 & 100.0 & 93 & 100.0 & 94 & 100.0 & 3 & 100.0 & 235 & 100.0 \\
\hline
\end{tabular}




\section{What is already known on this topic}

There has been interest in purposeful heading during soccer as a risk factor for brain injury. This subject is controversial. Initial studies of professional soccer players from the Netherlands concluded that prolonged exposure to heading could lead to neurological and neuropsychological problems. Similar studies conducted elsewhere failed to identify such associations.

accounting for less than 10 cases a year, almost all of them minor.

This study is important because it represents one of the largest contemporary analyses describing the epidemiology of youth soccer injuries requiring emergency medical care. Such analyses can be of value in directing prevention efforts. The current position of organisational bodies such as the Canadian Soccer Association is that heading should remain as an inherent part of the game, and that prevention efforts should focus on education and training. ${ }^{20}$ A staged approach to instruction is suggested. ${ }^{20}$ Players as young as 6-7 years may be taught proper heading technique (eyes open, mouth shut, make ball contact on the hairline, and step forward as the ball is contacted), but a small or soft ball should be used during instruction. As players progress, they should be encouraged to "head through" (ages 8-9) then "attack" (ages $10-12$ ) the ball with a stiff neck and arched back. ${ }^{20}$ These concepts promote mastery of the technique while at the same time minimising potential for injury.

Other potential options for primary prevention include age restrictions surrounding the introduction of heading, use of light protective headgear, the efficacy of which is supported by impact biomechanical experiments, ${ }^{21}$ or even prohibition of heading in the game. In view of our emergency department findings, these suggestions may be premature given the fact that minor head injuries and concussions are rare events, and when head injuries do occur they are generally not associated with purposeful heading of the ball. Rather, they are associated with player to player contact, being struck by a kicked ball, or (more rarely) contact with a goal post.

Other researchers have identified collisions with other players to be a leading mechanism of soccer injury, ${ }^{22} 23$ and hence a primary injury control priority. ${ }^{24}$ This particularly applies to head to head contact during the course of play. Although it was not possible to determine how many of our injuries were due to player infractions, most head and other injuries were sustained during organised practices and games. This points to the need for vigilance in rule enforcement by referees, with support from provincial and district associations, clubs, coaches, and other playing staff. Competitive advantages gained through aggressive play also need to be counter balanced with respect for one's opponent and the game itself.

Eye injuries from ball contact represent an important issue in soccer, ${ }^{25}{ }^{26}$ and this was supported in our population based case series. Nearly half (27/62) of the head injuries sustained from ball contact were injuries to the eye. Follow up care in a regional eye clinic was routinely advised. Because of the threat of neurotrauma, there has been a move in organised soccer towards the use of smaller ball sizes at younger ages. Although this may confer some protection on players, we speculate that ocular injuries may increase as a consequence.

Our analysis informs one aspect of the debate surrounding the practice of heading in youth soccer: heading is rarely associated with acute injury. Although this is an important finding, several limitations warrant recognition.
What this study adds

This study contributes to this debate by examining a large, Canadian sample of acute soccer injuries requiring emergency treatment. Among youth players, we found little evidence that the purposeful heading of the ball was an important source of acute injury. Player to player contact injuries were a more important concern.

Firstly, our analysis can only be related to the contemporary game. Innovations in manufacturing have led to water resistant and lighter weight soccer balls, and comparative historical data do not exist. These changes to soccer balls have been widely accepted and have improved the game itself.

Secondly, this analysis only considered acute soccer related injuries that presented for emergency medical care. These visits represented only a portion of the injuries that require and/or receive medical attention. It was not possible to determine the number of such injuries treated in physicians' offices and outpatient clinics, or identify players that did not seek medical care. Because of a lack of general exposure data, it was also not possible to calculate meaningful rates of soccer head injury. However, the CHIRPP injury surveillance system in Kingston has been shown to be fully representative of all medically treated injuries experienced by youth in terms of patterns of injury observed by external cause. ${ }^{27}$

Thirdly, debate surrounding the practice of heading in soccer goes beyond the occurrence of acute injury. There are other medical consequences that we were unable to consider. Foremost of these are long term neurological sequelae- the heart of the "heading debate". ${ }^{12}$ The potential for neurological problems has been suggested in the original Norwegian studies of professional athletes, ${ }^{6-11} 2829$ one study of amateur soccer players, ${ }^{13}$ and laboratory simulations. ${ }^{163031}$ It is impossible to identify chronic neurological problems within our existing emergency department based injury surveillance programme.

Finally, descriptions of injury circumstances were based on self reports collected as part of an established surveillance programme. The CHIRPP system was not developed exclusively for the study of soccer injuries, which limits detail at the record level. For example, the exact natures of the playing circumstances or physical descriptions of injury producing events are rarely available, and descriptions of external cause are based on close ended coding items that are not always illustrative. Up to $15 \%$ of patients that present to emergency departments are unable or unwilling to complete the CHIRPP surveillance form (K Bowes, Nurse Coordinator, Kingston CHIRPP, personal communication, 2004), and in these situations injury descriptions are provided by a proxy respondent or abstracted from the medical record. This process too may lead to misclassified or non-specific data reports. With respect to diagnostic information, although standard approaches to the triage and initial management of these injuries are in place, emergency doctors vary in their approach to patient management. This may lead to varying and non-specific diagnoses being recorded on the medical chart and hence the CHIRPP surveillance record. Caution is warranted in the interpretation of some diagnoses-for example, those that require radiological evidence-as these may have been based on variable amounts of information.

\section{CONCLUSION}

This analysis examined youth soccer injuries in Kingston, Canada over a six year period, with a specific focus on acute head injuries that present for emergency medical care. The 
results indicate the importance of several external causes of acute soccer head injury and how these vary by age group. The occurrence of acute head injuries appears to be uncommon among youth players, and very few appear to be attributable to the practice of purposefully heading the ball. Injuries caused by player contact appear to be a more important concern.

\section{Authors' affiliations}

W Pickett, S Streight, K Simpson, R J Brison, Department of Emergency Medicine and Department of Community Health and Epidemiology, Queen's University, Kingston, Ontario, Canada

Competing interests: none declared

\section{REFERENCES}

1 Guskiewicz KM, Marshall SW, Broglio SP, et al. No evidence of impaired neurocognitive performance in collegiate soccer. Am J Sports Med 2002;30:157-62.

2 Lobnes JH, Garret WE. Soccer in sports medicine: the school of the aged athlete, 2nd ed. Philadelphia: WB Saunders, 1996:715-27.

3 Nilsson S, Roaas A. Soccer injuries in adolescents. Am J Sports Med 1978;6:358-61.

4 Powell JW, Barber-Foss KD. Traumatic brain injury in high school athletes. JAMA 1999;282:958-63.

5 Janda D, Bir C, Cheney A. An evaluation of the cumulative concussive effect of soccer heading in the youth population. Inj Control Saf Promot 2002;9:25-31.

6 Tysvaer AT, Storli OV. Soccer injuries to the brain. A neurologic and electroencephalographic study of active football players. Am J Sports Med 1989; 17:573-8.

7 Sortland O, Tysvaer AT. Brain damage in former association football players. An evaluation by cerebral computed tomography. Neuroradiology 1989;31:44-8.

8 Tysvaer A, Storli O. Association football injuries to the brain. A preliminary report. Br J Sports Med 1981;15:163-6.

9 Tysvaer AT, Storli OV, Bachen IN. Soccer injuries to the brain. A neurologic and electroencephalographic study of former players. Acta Neurol Scand 1989;80:151-6.

10 Tysvaer AT, Lochen EA. Soccer injuries to the brain. A neuropyschologic study of former soccer players. Am J Sports Med 1991;19:56-60

11 Haglund $Y$, Eriksson E. Does amateur boxing lead to chronic brain damage? A review of some recent investigations. Am J Sports Med 1993;21:97-109.

12 Kirkendall DT, Garrett WE Jr. Heading in soccer: integral skill or grounds for cognitive dysfunction? J Athl Train 2001;36:328-33.

13 Matser EJ, Kessels AG, Lezak MD, et al. Neuropyschological impairment in amateur soccer players. JAMA 1999;282:971-3.

14 Jordan SE, Green GA, Galanty HL, et al. Acute and chronic brain injury in United States National Team soccer players. Am J Sports Med 1996;24:205-10.

15 Kirkendall DT, Jordan SE, Garrett WE. Heading and head injuries in soccer. Sports Med 2001;31:369-86.

16 Queen RM, Weinhold PS, Kirkendall DT, et al. Theoretical study of the effect of ball properties on impact force in soccer heading. Med Sci Sports Exerc 2003;35:2069-76.

17 Prabhu VC, Bailes JE. Chronic subdural hemtoma complicating arachnoid cyst secondary to soccer-related head injury: case report. Neurosurgery 2002;50:195-7.
18 Mackenzie SG, Pless IB. CHIRPP: Canada's principal injury surveillance program. Canadian Hospitals Injury Reporting and Prevention Program. Inj Prev 1999;5:208-13.

19 Health Canada. Canadian Hospitals Injury Reporting and Prevention Program Coding Manual. Ottawa: Laboratory Centre for Disease Control, Health Canada, 1996.

20 Canadian Soccer Association. Coaching at the grass roots: it's practice time! http://www.canadasoccer.com (accessed 20 Aug 2004).

21 Broglio SP, Ju Y, Broglio MD, Sell TC. The efficacy of soccer headgear. J Athl Train 2003;38:220-4.

22 Barnes BC, Cooper L, Kirkendall DT, et al. Concussion history in elite male and female soccer players. Am J Sports Med 1998;26:433-8.

23 Boden BP, Kirkendall DT, Garrett WE. Concussion incidence in elite college players. Am J Sports Med 1998;26:238-41.

24 McCrory PR. Brain injury and heading in soccer. BMJ 2003;327:351-2.

25 Capao Filipe JA, Fernandes VL, Barros H, et al. Soccer-related ocular injuries. Arch Ophthalmol 2003;121:687-94.

26 Horn EP, McDonald HR, Johnson RN, et al. Soccer ball-related retinal injuries: a report of 13 cases. Retina 2000;20:604-9.

27 Pickett W, Brison RJ, Mackenzie SG, et al. Youth injury data in the Canadian Hospitals Injury Reporting and Prevention Program: do they represent the Canadian experience? Inj Prev 2000;6:9-15.

28 Downs DS, Abwender D. Neuropsychological impairment in soccer athletes. J Sports Med Phys Fitness 2002;42:103-7

29 Matser JT, Kessels AG, Jordan BD, et al. Chronic traumatic brain injury in professional soccer players. Neurology 1998;51:791-6.

30 Naunheim RS, Standeven J, Richter C, et al. Comparison of impact data in hockey, football and soccer. J Trauma 2000;48:938-41.

31 Putukian M. Echemendia RJ, Mackin S. The acute neuropsychological effects of heading in soccer: a pilot study. Clin J Sport Med 2000;10:104-9.

\section{COMMENTARY}

This is a valuable study that provides unique data on this important topic. The study would be strengthened by a uniform definition of what constitutes a "head injury". Young children should have been analysed given that the proportion of all injuries that were to the head was higher in those younger than 10 years than those older than $10(25 \% \mathrm{v}$ $14 \%)$. Readers should also note that this report only captures those patients arriving at emergency departments who complete the database forms. Unconscious patients and the very large numbers of patients who do not attend the emergency departments but in fact have sustained a brain or other important injury are not included. In this sense the results are not representative of the entire picture, and more research is needed.

M Cusimano

St Michael's University Hospital, Division of Neurosurgery, Toronto, Ontario M5B 1A6, Canada; injuryprevention@smh.toronto.on.ca 